BIM in infrastructure design and engineering 


\title{
Infrastructural BIM standards - Development of an Information Delivery Manual for the geotechnical infrastructural design and analysis process
}

\author{
M. Obergriesser \\ University of Applied Science Regensburg, Construction Informatics Group, Regensburg, Germany \\ A. Borrmann \\ Technical University Munich, Chair of Computational Modeling and Simulation, Munich, Germany
}

\begin{abstract}
Defining infrastructural BIM standards is an essential issue to successfully implement BIM in the civil engineering domain and to gain acceptance of engineers, software developers and executive users. For this reason the paper proposes a way to improve collaboration between the geomechanical infrastructural design and analysis process, by introducing an infrastructural Information Delivery Manual (IDM). To realize IDM, the traditional geomechanical infrastructural use case was defined and the process specific workflow (activities \& data exchange) was determined by developing an infrastructural process map. In order to ensure correct data exchange between the involved processes various Exchange Requirements (ER) were specified. But to the effect an infrastructural product model like IFC is still not available, the data exchange as well as the ER specification was made by different formats. At the end of this research activity the Model View Definition (MVD) was discussed.
\end{abstract}

\section{INTRODUCTION}

\subsection{Overview}

The Building Information Modeling method is widely known and adopted in the building industry. It is the bases to ensure a continuous and consistent planning, construction and maintaining process during the whole building lifecycle. Using the BIM methodology enables architects, engineers, constructors (AEC), operator and owner to create, deliver, and adjust all required semantical and geometrical building data. But the success of the Building Information Modeling approach depends on different core components (see section 1.4).

The building industry itself is divided into two main sections - the structural engineering (SE) and the civil engineering (CE) domain. Unfortunately, almost all $\mathrm{BIM}$ research as well as developed BIM approaches are only realized for the SE field. This might be due to the fact that the geometrical objects are simpler in their structure, the reuse of equal objects like doors, windows, columns or entire floors occurs frequently or the implementation of new 3D modeling methods was easier to realize as in the civil engineering industry. Further, a lot of BIM specific SE standards were developed, maintained and supported by researchers, industry experts and the buildingSMART organization (BISM 2012).

But are there standards available for the civil engineering sector? Which existing structural engineering
BIM concepts could be adopted to the infrastructure process? And which traditional civil engineering designing processes have to be changed?

Different research organizations like the NIST, GeorgiaTech, VTT, University Osaka or the TUM deal with these questions. The German research project "ForBAU" (ForBAU 2008), for example, developed different concepts creating 3D parametric road and bridge models. Researchers from Japan proposed a new concept defining a product model for shield tunnel projects (Yabuki 2008) and in further countries like Korea (Shim 2012), Finland (Hyvärinen et al. 2010), Franc (Lebéque et al. 2005) or the USA (IFCInfra 2011) similar projects have been launched. The aim of all these infrastructural projects is to identify different solutions realizing a standardized infrastructural Building Information Model. In 2011 the buildingSMART organization established the openINFRA initiative (Newsletter 2011) in order to push forward the global implementation of the infrastructural BIM approach.

\subsection{Motivation}

Until now several excellent proposals have been developed in order to introduce and implement the BIM approach within the SE field. However, to reach this level for the CE sector a lot of research is still necessary.

At the moment, most parts of the geotechnical and infrastructural process occur in a traditional $2 \mathrm{D}$ based 


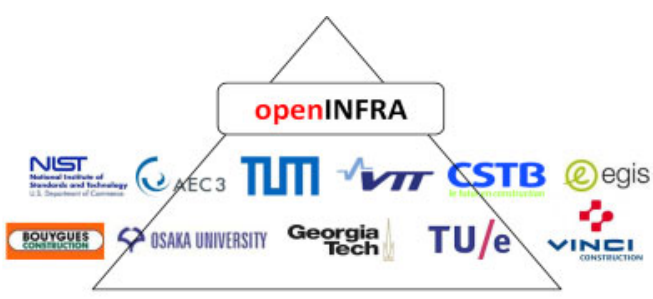

Figure 1. openINFRA initiative.

way allowing engineers to concentrate on their specific task. But if changes occur every engineer has to redesign his two dimensional design, which results in a very ineffective, time consuming and inconsistent process. Another problem consists in the poor collaboration of the different organizations involved in the planning process. In most cases each sector devises its designing tasks alone and without any information transfer to other designing fields (Kaminski 2010). However, if data exchange occurs, either engineers have to remodel the system by interpreting the outprint of the geometrical and sementical information or they have to prepare they integrated digital data. For example within the geotechnical analyzing process, where a digital exchange of geometrical cross section and semantical subsoil properties is not possible engineers has to implement the necessary information by remodeling each significant cross section manually.

An analysis of the organization of the entire geotechnical infrastructure process reveals a further problem. Currently the workflow is not structured and is based on fixed timeslots or the experience of several project managers. A detailed description of an ideal infrastructure process is not yet defined.

If the BIM methodology should be applied to the infrastructural domain there need to be means to store and maintain all geometrical and semantical information into one parametrical product model. Unfortunately the Industry Foundation Class (IFC) cannot full-fill the $\mathrm{CE}$ demands up to now. Additional different software is needed to enable civil engineers to design a 3D parametric infrastructure model. The different software like Autodesk Revit, Tekla Structures or Bentley Architecture in the SE sector is not suitable to realize the BIM approach in the infrastructural sector.

\subsection{Related work}

In 1994 different researchers from France and Japan started to develop an IFC-Bridge product model. This format is based on the IFC data schema (Yabuki et al. 2006, Lebéque and Arthaud 2007) and was extended by a rich set of bridge specific entities necessary to exchange the geometrical and semantical information of the bridge model. To ensure an exchange of parametric bridge specific values $\mathrm{Ji}$ extended the defined IFC-Bridge format by further parametric entities (Ji et al. 2011).

Researcher identified that the interaction between the bridge and road structure is based on the same

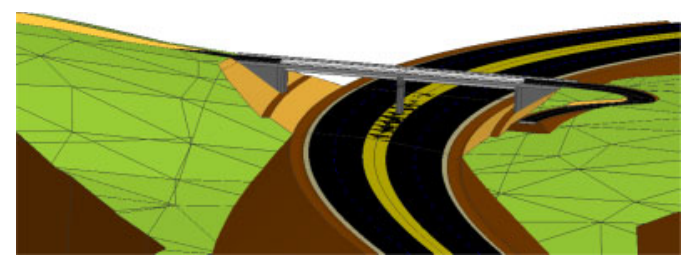

Figure 2. Parametric 3D-Infrastructure model.

geometrical elements. Especially as the routing of the bridge model depends on the course of the roadway model. In order to integrate this strong boundary condition as well as to improve the description of the entire road and bridge environment, the IFC-Road initiative was launched in 2005 (Lebéque 2005). Both product models were associated in IFC-Infra (Lebégue 2011).

One of the big aims into the research project "ForBAU - The virtual construction site" was to investigate how a digital road and bridge model could be realized using parametric 3D modeling methods (Borrmann et al. 2009). In order to implement this task different powerful freeform modeling applications from the automotive and building industry were tested and compared (Obergrießer 2011). Finally a concept was proposed to realize a parametric infrastructure model which consists of a subsoil, terrain, road and bridge model (compare figure 2).

Obergriesser et al. 2011 suggested a concept integrating the geotechnical and infrastructural design and analysis process using a parametric and 3D based approach. First a 3D parametric infrastructure model is generated automatically by integrating the different roadway cross sections via LandXML-format. In a second step the 2D geomechanical analyses occurs by integrating the same cross sections into the system and combine it with the corresponding subsoil properties (Obergriesser et al. 2009). After the analyzing process was finished the results are transferred back to the parametric model.

To improving the collaboration within the entire design, bid and building (DBB) process, different task-specific concepts are suggested using Information Delivery Manual (IDM). During the last view years researchers and industry experts developed a lot of IDM proposals. Eastman for example defined a very detailed IDM standard for the architectural precast DBB process (Eastman et al. 2010). In order to ensure that the different proposed IDM's become a standard the buildingSMART organization established the National BIM Standard (NBIMS) which has the responsibility to collect, provide and maintain the defined standards (NBIMS 2007).

First investigation occurs to develop an infrastructural specific IDM approach. The Technical Research Centre of Finland (VTT), for example, started first studies to define a general infrastructural process map (Hyvärinen et al. 2010) and the National Institution of Standards and Technology (NIST) published a highlevel process map about the entire DBB infrastructure process (Palmer 2011). 


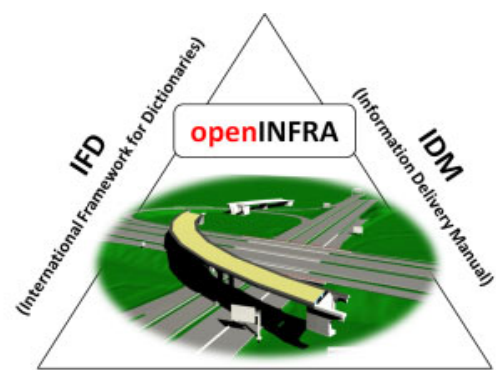

(Industry Foundation Class for Bridge) (Geo-referenced Extensible Markup Language)

Figure 3. buildingSMART standards.

Researchers are convinced that the definition of a process specific standard will improve the application of BIM within the building industry (Hietanen 2006, Aram 2010, Venugopal 2012).

\subsection{Building information modeling standards}

Experience has shown that the different branches of civil engineering have developed their own concepts of BIM. As a result, terminologies, data formats and work processes differ. To solve the non-uniform thread of BIM approach the buildingSMART organization introduced three technologies due to standardizes the three core components - terminology, digital storage and work processes (BISM 2012).

1. Terminology: Almost all countries use another vocabulary for the same building objects or interpret it in different ways. These different definitions lead to misunderstandings in international collaboration. In order to improve this situation buildingSMART introduced the international framework of dictionaries (IFD) library which includes a technology standardizing the definition of building objects. Further, using IFD standards keep control of building terminology and guarantee the exchange of building data (Grant 2008).

2. Digital Storage: At the beginning of Computer Aided Design (CAD) the interoperability between different designing processes often failed because there was no standard format available exchanging all geometrical and semantical building data during the entire building lifecycle. Due to this reason the IFCformat (Eastman 1999, Wix 2007a, Liebich 2009) was launched by the International Alliance for Interoperability (IAI) in 1994. Since, different researchers and industry experts have improved and extended the IFC product model in order to set an international standard.

3. Work Processes: Different DBB processes like preliminary design, detailing, fabrication, construction or maintenance are some of the tasks necessary for the construction of a building. But how, with which means and at what time these different processes should be executed is not defined. This missing organization leads to additional problems within the BIM process. Therefore a concept was introduced providing a standard for the building industry DBB process. This standard is called Information Delivery Manual
(IDM) (Wix 2007b) and consists of three main components (for a detailed described see section 2.1) enabling researchers and industry experts to develop a correct process (Kalderén 2010, Eastman et al. 2010, Berard et al. 2011).

Currently all different standards are developed for the SE sector only. However, in order to realize BIM within the civil engineering domain CE specific standards are necessary. The implementation of an infrastructural IFD library is not yet on the stocks but the OmniClass construction classification system (OmniClass 2006, Grant and Ceton 2008) could be a good point to start. As mentioned in section 1.3 first infrastructural product models and first proposals how to define a standardized infrastructural DBB process already exist. The focus of this paper is to use the suggested high-level DBB infrastructure process map from Chen and extend it to further sub-processes like the geomechanical and infrastructural process.

\section{INFRASTRUCTURAL INFORMATION DELIVERY MANUAL}

\subsection{IDM components}

The purpose of an IDM is to capture all the knowledge and experience from an AEC experts group to define the specific workflow (Use Case) as well as the most effective way to exchange data between the different users. To realize this scope the IDM approach is divided into three parts - Process Map (PM), Exchange Requirements (ER) and Model View Definition (MVD) - described into the next few sections.

\subsection{Geomechanical infrastructural use case}

The entire infrastructural design and analysis process is a combination of the subsoil investigation, terrain surveying and the transportation design task and is completed by the geomechanical analysis process. In order to define a correct IDM standard the sequence of the four involved tasks is described shortly.

The infrastructural project starts with the investigation and interpretation of the subsoil. Therefore different core specimens and pressure detections are extracted and analyzed by geotechnical engineers. After this process the received results are summarized into a geotechnical subsoil report which includes information about the different subsoil layer locations and properties. Parallel to the subsoil task a team of surveyors creates a measurement of the entire infrastructural landscape using tacheometric or laser scanning techniques. At the end of this process a finite set of surveying points is recorded which enables engineers to create a Digital Terrain Model (DTM). In order to realize the transportation design task at first the DTM is integrated into a system. After that the roador railway model is created by using three different $2 \mathrm{D}$ drawings. First the horizontal alignment is designed into the horizontal plan (x-y-plane); second the vertical plan (x-z-plane) is derived from the horizontal 


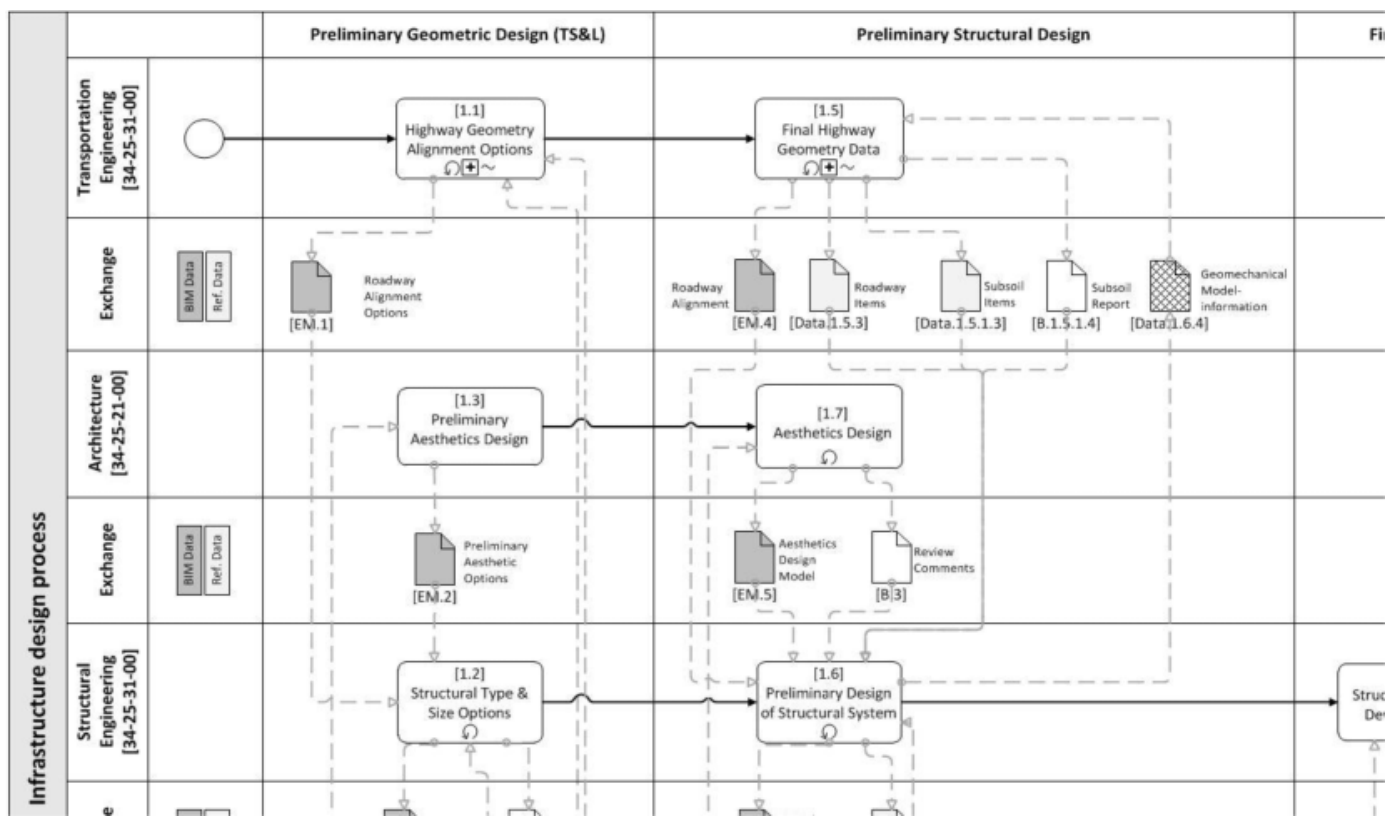

Figure 4. Excerpt of the entire infrastructural DBB process map.

plan and enables engineers to construct the vertical alignment (gradient) and finally the geometrical definition of the profile happens (y-z-plane). Applying this traditional method allows engineers to concentrate on the three specific geometrical designing tasks. After this iterative process the implicitly described 3D road- or railway model could be generated and the geomechanical analysis process could start. Therefore a structural engineer remodels each significant cross section by interpreting the derived 2D cross section from the model and combines it with the corresponding subsoil properties. After the analyzing process was finished the results are summarized into a report and transferred back to the transportation design task and the iteration starts.

\subsection{Process map}

To point out problems within the traditional infrastructure process, the development of the infrastructural process map was divided into several steps. In a first step a preliminary process map was defined displaying the traditional geomechanical and infrastructural process (as described in section 2.2). In a second step this preliminary map was analyzed in order to identify the specific problems in the traditional infrastructure process and to find solutions to them. Finally an improved process map was designed extending the traditional one with new necessary processes and exchange standards (displayed by hatched elements in figure $4 \& 5$ ).

The infrastructural process map is supposed to include all process specific information needed to describe the entire infrastructural process. Therefore, in a first step, process dependencies, sequences, data exchange points and other process specific information were summarized. To ensure a standardized layout of the proposed process map the Business Process Modeling Notation (BPMN) was used. BPMN itself is a specification to create business specific process diagrams by utilizing a common language and convention (Owen and Raj 2003, White 2003). Due to using various elements (activities, events, gateways, data and swimlanes) a general infrastructural process map was designed which ensures communication with each involved user (manager, industry experts or software developer). Further by applying a top down approach a hierarchical tree structured process map was designed.

For illustration figure 4 shows an excerpt of the high-level infrastructural process map (Chen 2011) consisting of a certain number of activities/processes. Furthermore, some of these processes like the 1.5 Final Highway Geometry Data process consist of additional sub-processes (see figure 5). By expanding or collapsing these processes (indicated by a plus sign) a higher or lower process level could be reached and ensures a readable and understandable form. If a process occurs several times (like the iterative transportation design process 1.5.3 in figure 5) than an arc with an arrow symbol is indicated, or if a process is executed into an unstructured (non-sequence) order than a tilde symbol is located on the bottom of the ad hoc sub-process. The sequence of the subsoil investigation or the terrestrial surveying process, for example is not determined. Due to this reason the process 1.5 Final Highway Geometry Data process is defined as an ad hoc sub-process.

Each process map consists of a pool which is divided into several horizontal and vertical swimlanes. Horizontal lanes deliver information about involved engineers classified by an OmniClass number and 


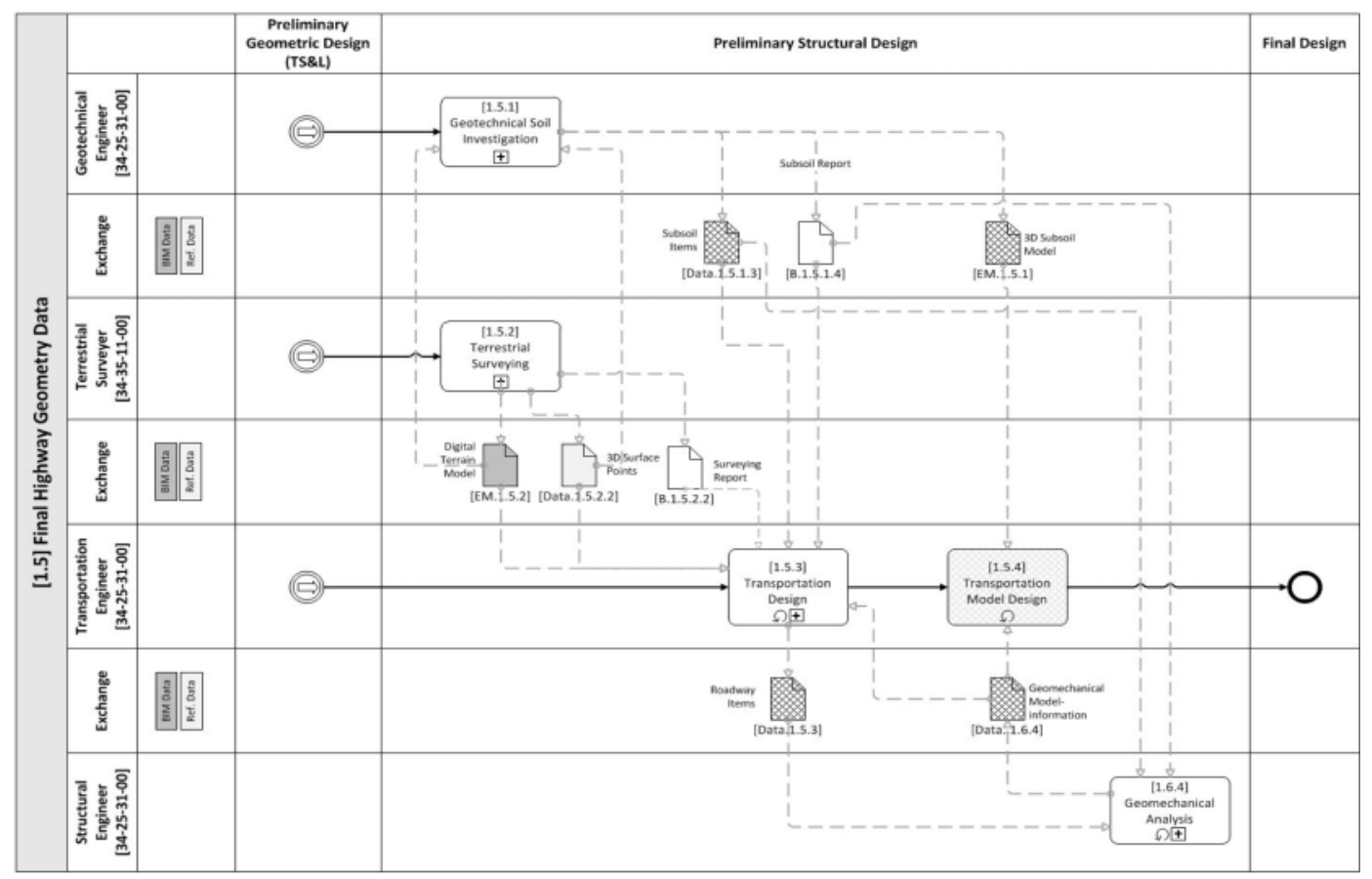

Figure 5. Detailed process map of the geomechanical infrastructural design process map.

shows which activities occur within the horizontal lane. The "Exchange" lane located between each engineer has a very important role because it shows the data exchange between the different engineers and activities as well as the delivery information about the type of data. Unfortunately the data exchange within one lane is not shown but the exchange between different lanes is indicated by a data element. As an infrastructural product model like IFC is still lacking, the data element consists of three different types (models, digital or out-printed drawings/reports). The sub-process 1.5 Final Highway Geometry Data process delivers, for example, the information to sub-process 1.6 Preliminary Design of Structural Design, by exchanging a 3 D roadway alignment model as an exchange model, the surveying points as a digital data and an the subsoil condition as an out-printed report. In most cases this mix leads to many problems within the entire DBB infrastructural process.

The vertical lanes support the reader with information at what time which process has to be executed. Further each new defined sub-process map includes one previous and following vertical and horizontal lane (see figure 5) which clarifies the boundary conditions of the regarded process. This improves the interpretability of the infrastructural process map.

\subsection{Exchange requirements}

An exchange requirement represents the link between data and process (Kalderén 2010) and determines a correct and process specific data exchange. Therefore a heading, an overview and an information section has to be defined for every data format by interpreting the involved process as well as the lifecycle of the corresponding BIM model.

Unfortunately, an infrastructural BIM model does not exist in the civil engineering domain. Due to this reason the different infrastructural processes are connected by various exchange formats like IFCBridge, LandXML, GroundXML, dxf, dwg, pdf. In order to adjust the exchange requirement to this situation the header section was extended to additional components like "data objects" which determines the required data. Table 1 shows for example the header section of a geomechanical and infrastructural exchange requirement.

\subsection{Model view definition}

MVDs represent the software developer interface of exchange. It is a conceptual process which defines the Exchange Requirement (ER) coming from the IDM process to the most logical Model Views that will be supported by software applications (Nawari, 2011). In this software implementation process a product model like the IFC format plays a central role because a correct implementation of the digital data into the different involved software ensures a successful BIM approach. Furthermore, the collaboration between the different processes as well software could be significantly improved. Not until a standard format for the infrastructural process has been developed an MVD can be implemented successfully. 
Table 1. Header page of the Data 1.5.1.3 and EM 1.5.2.
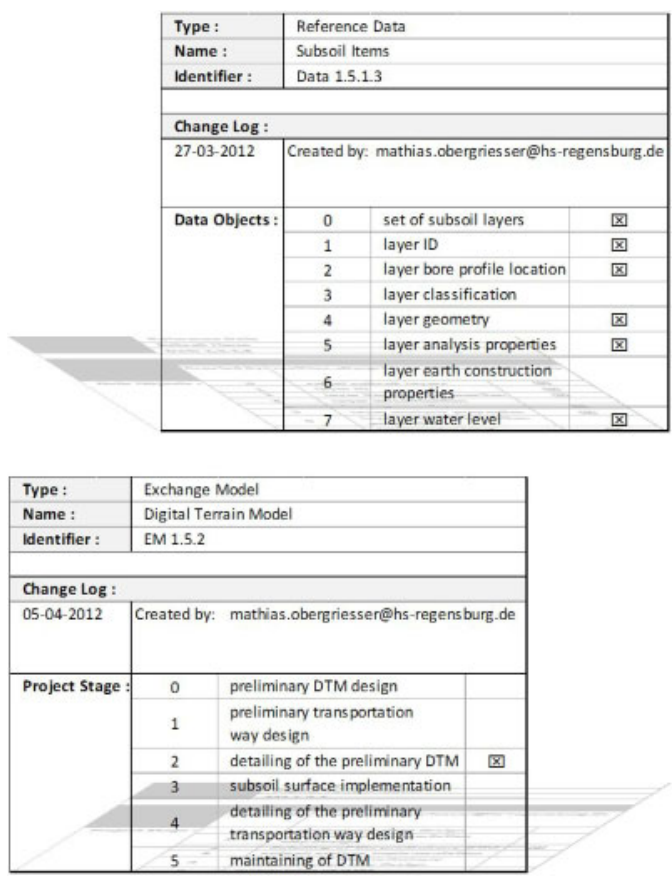

\section{DISCUSSION \& FURTHER WORK}

The paper has introduced a new IDM standard for geomechanical infrastructural processes. Therefore the problems in practice were described and different solutions were suggested by defining an infrastructural process map and exchange requirements (section 2). Furthermore, a general overview about the current research work within the infrastructural domain was summarized in section 1.

This paper points out that the implementation of the BIM method within the infrastructural designing, bidding and building industry needs different standards in order to be accepted by engineers, software developers and executive users. Only after this process infrastructural projects can be successfully completed. Therefore future research work is needed regarding the definitions of an infrastructural MVD and the development of an infrastructural product model.

In a next step the author will develop further geomechanical and infrastructural ER's as well as detail the high-process map by defining a sub-process map for the structural bridge design.

\section{REFERENCES}

Aram, S., Eastman, C., Sacks, R., Panushev, I., Venugopal, M. (2010). Introducing a new methodology to develop the information delivery manual for AEC projects, In: Proc. of the CIB W78 2010: 27th International Conference, Cairo, Egypt.

Berard, O., Karlshoej, J. (2011). Information delivery manuals to integrate building product information into design,
In: Proc. of the CIB W78 2011: 28th International Conference, Sophia Antipolis, France.

BISM. (2012). buildingSmart standards. <http://buildingsmart.com/standards $>$ (28-03-2012).

Borrmann, A., Ji, Y., Wu, I-C., Obergrießer, M., Rank, E., Klaubert, C, Günthner, W. (2009). ForBAU - The virtual construction site project, In: Proc. of the 24th CIB-W78 International Conference, Istanbul, Turkey.

Chen, S. (2011). Process Map IBC. University at Buffalo, structural and earthquake engineering.

Eastman, C. (1999). Building product Models: Computer Environments, Supporting Design and Construction, CRC, Boca Raton, Fla., 287-315.

Eastman, C., Jeong, Y-S., Sacks, R., Kaner, I. (2010). Exchange Model and Exchange Object Concepts for Implementation of National BIM Standards, Journal of Computing in Civil Engineering, 24(1), 25-34.

ForBAU. (2008). Research project ForBAU - The virtual construction site. <www.forbau.de> (10-04-2012).

Grant, R. (2008). IFD Library White Paper, BuildingSMART. <www.ifd-library.org/images/IFD_Library_White_Paper_ 2008-04-10_I_.pdf> (09-03-2012).

Grant, R. and Ceton, G. (2008). OmniClass and IFD Library, BuildingSMART. <www.omniclass.org/CSI_OmniClassIFD_2008.pdf $>(08-03-2012)$.

Hietanen, J. (2006). Information delivery manual guide to components and development methods, BuildingSMART, Oslo, Norway.

Hyvärinen, J., Mäkeläinen, T., Rekola, M., Tömqvist, J. (2010). InfraTimantti esiselvitys Loppuraportti, VTT, Finland.

IFC-Infra. (2011). Overview of the IFC-Infra meeting Paris 2011. <www.communic.fr/ifc_infra_meeting_english. htm $>(25-01-2012)$.

Ji, Y., Borrmann, A., Obergriesser, M. (2011). Towards the Exchange of Parametric 3D Bridge Models Using a Neutral Data Format, Proceedings of the 2011 ASCE International Workshop on Computing in Civil Engineering, 528-535.

Kalderén, B. (2010). Information Delivery Manual Guide to Components and Development Methods, BuildingSMART. <www.iai.no/idm/idm_resources/idm_methods_ guides/IDMC_004_1_2.pdf $>$ (08-12-2011).

Kaminski, I. (2010). Potenziale des Building Information Modeling im Infrastrukturprojekt - Neue Methoden für einen modellbasierten Arbeitsprozess im Schwerpunkt der Planung, Dissertation, Universtät Leipzig, Leipzig.

Lebéque, E. (2005). IFC Bridge \& Road Workshop. BuildingSMART, CSTB, Sophia-Antipolis, France. $<$ http:// salle-immersive.cstb.fr/en/file/rub19_doc34_6.pdf> (0512-2011)

Lebéque, E. and Arthaud, G. (2007). IFC Bridge V2 Data Model, BuildingSMART, CSTB, France.

Lebéque, E. (2011). IFC Bridge Experience - The development process, IFC-Infra meeting, Paris, 2011.

Liebich, T. (2009). IFC 2x Edition 3 Model Implementation Guide, Version 2.0, buildingSMART international, AEC3, Germany.

Nawari, N. (2011). Standardization of Structural BIM, Proceedings of the 2011 ASCE International Workshop on Computing in Civil Engineering, 405-412.

Newsletter. (2011). Open standards for infrastructure, buildingSMART. $\quad<$ http://bw-dssv07.bwk.tue.nl/files/ news-letters/buildingsmart-newsletter-august-2011>(0304-2012).

Obergrießer, M., Ji, Y., Baumgärtel, T., Euringer, T., Borrmann, A., Rank, E. (2009). GroundXML - An addition of alignment and subsoil specific cross-sectional data 
to the LandXML scheme. In: Proc. of the 12th International Conference on Civil, Structural and Environmental Engineering Computing, Madeira, Portugal.

Obergrießer, M., Euringer, T., Horenburg, T., Günthner, W. (2011). CAD-Modellierung im Bauwesen: Integrierte 3D-Planung von Brückenbauwerken, In: 2. ForBAU Kongress, München. $<$ http://www.fml.mw.tum.de/forbau/ index.php? Set_ID $=496>(28-02-2011)$.

Obergriesser, M., Euringer, T., Borrmann, A., Rank, E. (2011). Integration of Geotechnical Design and Analysis Processes Using a Parametric and 3D Model Based Approach, Proceedings of the 2011 ASCE International Workshop on Computing in Civil Engineering, 430-437.

Owen, M. and Raj, J. (2003). BPMN and Business Process Management - Introduction to the New Business Process Modeling Standard. Popkin Software Guide.

OmniClass. (2006). Omniclass: A strategy for classifying the built environment, introduction, and user guide, 1.0 edition, Construction Specification Institute, Arlington, Va., $<\mathrm{http}$ ://www.omniclass.org $>$ (19-01-2012).

Palmer, M. (2011). U.S Interoperability Initiatives for Advancing Infrastructure Delivery, IFC-Infra meeting, Paris, 2011.
Shim, C-S., Lee, K-M., Kang, L., Hwang, J., Kim, Y. (2012). Three-Dimensional Information Model-Based Bridge Engineering in Korea, Scientific Paper of Structural Engineering International, 1/2012, 8-13.

Venugopal, M., Eastman, C., Sacks, R., Teizer, J. (2012). Semantics of model views for information exchanges using the industry foundation class schema, Journal of Advanced Engineering Informatics, 26(2012), 411-428.

White, S. (2003). Process Modeling Notations and Workflow Patterns. IBM Corp., United States.

Wix, J. (2007a). Information Delivery Manual Guide to Components and Development Methods, BuildingSMART. <ftp://ftp.iai.no/pub/idm/Methodology/IDM_GNU_Free_ Document_Licence.pdf $>$ (19-01-2012).

Wix, J. (2007b). What is IFC, buildingSMART international, AEC3, Germany.

Yabuki, N., Lebegue, E., Gual, J., Shitani, T., Zhantao, L. (2006). International collaboration for developing the bridge product model IFC-Bridge. Proc. of the 11th Int. Conf. on Computing in Civil and Building Engineering.

Yabuki, N. (2008). Representation of caves in a shield tunnel product model. In: Proc. of the 6th European Conference on Product and Process Modeling (ECPPM). Sophia-Antipolis, France. 